\title{
The Role of Whole Blood Viscosity Estimated by De Simone's Formula in Evaluation of Fractional Flow Reserve
}

\author{
(1) Ahmet Akdi, (1) Elif Hande Çetin, (1) Özge Çakmak Karaaslan, (1) Mehmet Akif Erdöl, \\ (1) Murat Oğuz Özilhan, (1) Orhan Maden, (1) Dursun Aras
}

University of Health Sciences Turkey, Ankara City Hospital, Department of Cardiology, Ankara, Turkey

\begin{abstract}
Objectives: Fractional flow reserve (FFR), which is an invasive technique, is appraised as the gold standard for physiological valuation of intermediate coronary disease. Because it is a pressure-linked measure, FFR can be influenced by whole blood viscosity (WBV). We aimed to evaluate the relationship between FFR and WBV, which can be calculated by a confirmed formula using only hematocrit and total serum protein levels.

Materials and Methods: We involved 226 patients who were implemented FFR after interpreting coronary artery angiogram. We separated the patients into two groups accordingly with the FFR cutoff value of 0.80: 96 patients (77.1\% male, mean age $62.84 \pm 9.90$ years) with critical stenosis as FFR $<0.80$ group and 130 patients $(76.9 \%$ male, mean age $63.32 \pm 11.0$ years) non-critical stenosis as FFR $\geq 0.80$ group. WBV at both low shear rate (L-SR) $(0.5$ sec- 1$)$ and high shear rate (H-SR) (208 sec-1) was computed by using total serum protein levels and hematocrit.

Results: Critical stenosis group had a remarkable increased WBV for both L-SR (52.85 \pm 21.23 vs. 43.90 \pm 22.30 , $\mathrm{p}=0.003)$ and H-SR ( $16.89 \pm 1.03$ vs. $16.45 \pm 1.09, \mathrm{p}=0.002)$. In the multivariate regression models, WBV both for L-SR [Odds ratio (OR): 1.018, 95\% confidence interval (CI): 1.004-1.032, $\mathrm{p}=0.010]$ and for H-SR (OR: 1.446, 95\% CI: 1.094-1.912, $\mathrm{p}<0.010$ ) was shown as an independent predictor of FFR value.

Conclusion: This study showed that high WBV was significantly associated with FFR values in the critical stenosis group.
\end{abstract}

Keywords: Fractional flow reserve, whole blood viscosity, de Simone's formula

Address for Correspondence: Ahmet Akdi, University of Health Sciences Turkey, Ankara City Hospital, Department of Cardiology,

Ankara, Turkey

e-mail: 17akdi@gmail.com ORCID: orcid.org/0000-0002-3428-1977

Received: 28.11.2021 Accepted: 09.01.2022

Cite this article as: Akdi A, Çetin EH, Çakmak Karaaslan Ö, Erdöl MA, Özilhan MO, Maden O, Aras D. The Role of Whole Blood Viscosity Estimated by De Simone's Formula in Evaluation of Fractional Flow Reserve. EJCM 2022;10(1):18-24.

DOI: 10.32596/ejcm.galenos.2022.2021-11-059

${ }^{\circ}$ Copyright 2022 by Heart and Health Foundation of Turkey (TÜSAV) / E Journal of Cardiovascular Medicine published by Galenos Publishing House. 


\section{Introduction}

It is of grant matter to assign the functional seriousness of angiographic moderate coronary artery stenosis for revascularization decision and clinical outcomes. Fractional flow reserve (FFR), which is the most important procedure used in the functional evaluation of anatomically moderate coronary lesions, calculates the capability of stenosis to cause myocardial ischemia by measuring aortic and the distal coronary pressures during maximum induced hyperemia ${ }^{(1)}$. FFR is independent of blood pressure changes but distal intracoronary pressure depends on flow which is affected by both microvascular and stenotic resistance in the lesions. Blood viscosity contributes to both stenotic and microvascular resistance thereby reducing distal blood flow and endangering tissue perfusion.

Whole blood is a non-Newtonian fluid, which means that its viscosity depends on shear rate and it can be calculated with an approved formula using the total plasma protein and hematocrit (HCT) levels ${ }^{(2)}$. Direct measurement of whole blood viscosity (WBV) showed no differences with coronary artery and peripheral artery samples ${ }^{(3)}$. As pressure and resistance dependent measurement, FFR may be affected by whole blood viscosity. By this study, we aimed to appraise the importance of WBV in the functional evaluation of angiographic moderate coronary stenosis.

\section{Materials and Methods}

\section{Patient Population}

We included 226 patients who underwent FFR between November 2014 and March 2016, since the severity of stenosis could not be evaluated clearly by angiography. All patients were referred to angiography due to evidence of ischemia on non-invasive testing or symptoms suggesting myocardial ischemia. FFR of all patients was performed according to certain standard practices by providing maximum hyperemia. De Simone et al. ${ }^{(4)}$ suggested calculating the WBV at $5.4-9.5 \mathrm{~g} / 100 \mathrm{~mL}$ for total serum protein level and ranges of $32 \%-53 \%$ for HCT. Therefore, we excluded the patients whose values were out of recommended ranges. Exclusion criteria were: Consecutive different intermediate stenosis in the same coronary artery, severe valvular lesions, hematological (myeloproliferative disorders, coagulopathies, hemoglobinopathies, anemia), inflammatory or oncological disease, renal (GFR $<30$ $\mathrm{mL} / \mathrm{min} / 1.73 \mathrm{~m}^{2}$ ), or hepatic insufficiency (metabolic and toxic liver disease, chronic and acute hepatitis).

The presence of at least one coronary artery stenosis with FFR $<0.80$ was accepted as evidence of critical stenosis. It was accepted that there was non-critical stenosis if the measured lesions had an FFR $\geq 0.80$. Previously, these cut-off values have been validated ${ }^{(5)}$. We separated patients into two groups: as FFR $\geq 0.80$ group, including 130 patients ( $76.9 \%$ male, mean age: $63.32 \pm 11.0$ years) with non-critical stenosis and as FFR $<0.80$ group, including 96 patients (77.1\% male, mean age: $62.84 \pm 9.90$ years) with critical stenosis. WBV for both high shear rate (H-SR) $\left(208 \mathrm{sec}^{-1}\right)$ and low shear rate (L-SR) $\left(0.5 \mathrm{sec}^{-1}\right)$ was computed from total protein and hematocrit levels by using the de Simon's formula.

Using the Modified Simpson's technique with transthoracic echocardiography (Vivid 7 Pro, GE, Horten, Norway), left ventricular ejection fraction was calculated. Diabetes mellitus was described as on antidiabetic treatment and having a fasting blood glucose measurement of 126 $\mathrm{mg} / \mathrm{dL}$ and above. Patients having a blood pressure value $>140 / 90 \mathrm{mmHg}$ or receiving an antihypertensive drug were defined as hypertensive. Patients taking hyperlipidemia medication or total cholesterol $>200 \mathrm{mg} / \mathrm{dL}, \mathrm{LDL}>130 \mathrm{mg} /$ $\mathrm{dL}$, triglyceride $>150 \mathrm{mg} / \mathrm{dL}$ were defined as hyperlipidemic and those active smoking or having quit smoking within the last year were defined as smokers. We conducted the study according to the institutional ethics committee and the ethical guidelines of the Declaration of Helsinki. Ethics Committee approval was obtained from University of Health Sciences Turkey, Ankara City Hospital with the number of E1-20-2030 in 2021. 


\section{Hemodynamic Measurements and Calculation of Fractional Flow Reserve}

FFR measurements of all patients were performed as in the routine of our clinic. It was put forward into the guiding catheter after a pressure detecting guidewire (PressureWire; St. Jude Medical Inc., St. Paul, MN, USA) was calibrated. After intracoronary pressure was measured and equal to the intra-aortic pressure in the guiding catheter, the pressure-sensor was placed $3 \mathrm{~cm}$ past the coronary target stenosis. Baseline distal intracoronary and intra-aortic pressures measurements were obtained. Then, they were obtained during induced maximum hyperemia with a bolus injection of intracoronary adenosine (starting at a dose of 40-80 $\mu \mathrm{g}$ to the left coronary artery and of $40 \mu \mathrm{g}$ to the right coronary artery, maximum dose of $250 \mu \mathrm{g}$ ). FFR value was computed as the proportion of the mean hyperemic distal intracoronary pressure in the guidewire to the mean intra-aortic pressure within the guiding catheter.

\section{Blood Sampling, Laboratory Tests, and Determination of Whole Blood Viscosity}

All patients' blood collection was performed routinely in our clinic. After 12-hour fasting, blood samples were gathered via an antecubital vein in suitable tubes. For the hematological test, tubes with EDTA and for biochemical tests, dry tubes, and a molecular analyzer (Roche Diagnostics, Mannheim, Germany) were used. Analyzer XE-1200 (Sysmex, Kobe, Japan) was used for white blood cell count (WBC), hemoglobin, hematocrit, erythrocyte count, and automated hematology measurement.

Estimation of WBV (cP: centipoise) at high shear rate (H-SR) $\left(208 \mathrm{~s}^{-1}\right)$ and low shear rate (L-SR) $\left(0.5 \mathrm{~s}^{-1}\right)$ was computed from the total plasma protein (TP, g/L) and hematocrit (HCT, \%) by previously approved formula ${ }^{(4,6)}$ :

WBV (cP: centipoise):

- at H-SR $\left(208 \mathrm{~s}^{-1}\right)=0.17(\mathrm{TP}-2.07)+(0.12 \mathrm{x} \mathrm{HCT})$

- at L-SR $\left(0.5 \mathrm{~s}^{-1}\right)=3.76(\mathrm{TP}-78.42)+(1.89 \times \mathrm{HCT})$

\section{Statistical Analysis}

Data were statistically analyzed by using SPSS 22.0 software package for the Windows version (SPSS Inc., Chicago, Ill., USA). Categorical variables were summarized as the count and percentage. The KolmogorovSmirnov analysis was used to evaluate the distribution of continuous variables and these variables were reported as the mean \pm standard deviation. In comparing the two groups were performed the Fisher's exact test or the chi-squared test for the categorical variables and student's t-test for the continuous variables. The linear association between WBV and FFR measurement values was evaluated by calculating the Pearson's correlation analysis. The effect of each different variable on the FFR result was calculated by univariate analysis. The variables assigned as likely risk factors in the logistic regression examination were included in the two models. Statistically, a significant p-value was accepted as less than 0.05 .

\section{Results}

The baseline laboratory findings and characteristics of both groups are given in Table 1. The study groups were similar regarding baseline parameters except for higher total plasma protein $(\mathrm{p}=0.009)$ and lower FFR measurement values $(\mathrm{p}<0.001)$ in the critical stenosis $(F F R<0.80)$ group. Cardiovascular drug use between both groups was statistically similar. The alterations between the WBVs of both groups are dedicated in Table 2. Critical stenosis (FFR $<0.80$ ) group had remarkably increased WBV at both L-SR $(52.85 \pm 21.23$ vs. $43.90 \pm 22.30, p=0.003$, Figure $1 \mathrm{~A})$ and H-SR (16.89 \pm 1.03 vs. $16.45 \pm 1.09, p=0.002$, Figure 1B). The correlation analysis showed an important associate between FFR value and both WBV at L-SR $(\mathrm{r}=-0.250, \mathrm{p}<0.001$, Figure 2A) and H-SR ( $r=-0.244, p<0.001$, Figure 2B).

The variables found to be unlike in univariate analysis were inclusive in multivariate logistic regression examination for determining the predictors of critical stenosis in FFR $(\leq 0.80)$. Two separate models were composed for WBV results at each shear rate in multivariate analysis. In models adjusted with both at LSR [Odds ratio (OR): 1.018, 95\% 

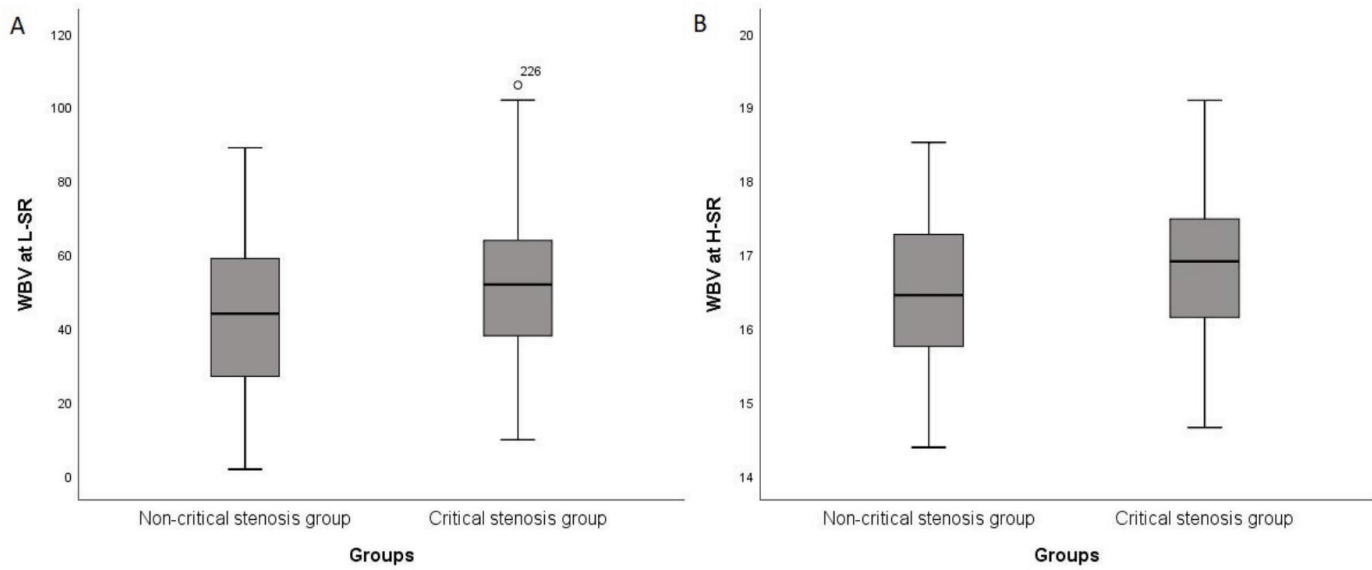

Figure 1. Comparison of WBV at L-SR (A) and H-SR (B) between patients with non-critical stenosis group (FFR $\geq 0.80)$ and critical stenosis group (FFR <0.80).

H-SR: High shear rate, L-SR: Low shear rate, WBV: Whole blood viscosity

Table 1. Baseline characteristics of patients with critical stenosis and non-critical stenosis group

\begin{tabular}{|c|c|c|c|}
\hline & $\begin{array}{l}\text { Non-critical stenosis group } \\
\text { (FFR } \geq 0.80)(n=130)\end{array}$ & $\begin{array}{l}\text { Critical stenosis group } \\
(\text { FFR }<0.80)(n=96)\end{array}$ & p-value \\
\hline Age (years) & $63.32 \pm 11.00$ & $62.84 \pm 9.90$ & 0.977 \\
\hline Gender (male) & $100(76.9)$ & $74(77.1)$ & 0.380 \\
\hline Diabetes mellitus, n (\%) & $38(29.2)$ & $38(39.6)$ & 0.103 \\
\hline Smoking, n (\%) & $34(26.2)$ & $35(36.5)$ & 0.096 \\
\hline Hypertension, n (\%) & $54(41.5)$ & $50(52.1)$ & 0.116 \\
\hline CABG, n (\%) & $4(3.1)$ & $5(5.2)$ & 0.418 \\
\hline PCl, n (\%) & $27(20.8)$ & $21(21.9)$ & 0.841 \\
\hline LVEF (\%) & $54.68 \pm 7.83$ & $53.98 \pm 6.78$ & 0.485 \\
\hline Hemoglobin (g/dL) & $14.15 \pm 1.45$ & $14.4 \pm 1.58$ & 0.218 \\
\hline Protein (g/dL) & $6.85 \pm 0.51$ & $7.03 \pm 0.53$ & 0.009 \\
\hline Glucose (mg/dL) & $126.27 \pm 56.44$ & $132.58 \pm 58.11$ & 0.413 \\
\hline Urea (mg/dL) & $35.55 \pm 9.87$ & $35.61 \pm 8.56$ & 0.957 \\
\hline Creatinine (mg/dL) & $0.98 \pm 0.20$ & $0.97 \pm 0.21$ & 0.862 \\
\hline Total cholesterol (mg/dL) & $190.36 \pm 38.72$ & $184.78 \pm 39.74$ & 0.293 \\
\hline LDL-C (mg/dL) & $118.02 \pm 32.14$ & $113.06 \pm 33.03$ & 0.258 \\
\hline HDL-C (mg/dL) & $41.57 \pm 10.42$ & $40.67 \pm 9.40$ & 0.503 \\
\hline Triglyceride (mg/dL) & $161.35 \pm 89.67$ & $161.60 \pm 78.91$ & 0.983 \\
\hline FFR measurement & $0.84 \pm 0.03$ & $0.71 \pm 0.05$ & $<0.001$ \\
\hline
\end{tabular}


confidence interval (CI): 1.004-1.032, $\mathrm{p}=0.010]$ and at HSR (OR: 1.446, 95\% CI: 1.094-1.912, $\mathrm{p}<0.010$ ), WBV was indicated as an independent predictor of the FFR (Table 3).

\section{Discussion}

The major consequents from this study were the following: WBV as a phrase of blood resistance to intracoronary flow has a relationship with functional severity of coronary stenosis. WBV has been demonstrated as an affecting factor of the consequence of FFR.

WBV, a crucial part of Virchow's triad, has been scarcely investigated due to the necessity for various materials during its measurement. On the other hand, de Simone et al. ${ }^{(4)}$ found a simple and non-invasive formula using HCT and total serum protein concentration for the computation of WBV at $\mathrm{H}-\mathrm{SR}$ and $\mathrm{L}-\mathrm{SR}^{(2,4)}$. These

Table 2. Comparison of WBVs at L-SR and H-SR between groups with and without significant stenosis in FFR

\begin{tabular}{|c|c|c|c|}
\hline & $\begin{array}{l}\text { Non-critical } \\
\text { stenosis group } \\
(\text { FFR }<0.80) \\
(n=130)\end{array}$ & $\begin{array}{l}\text { Critical } \\
\text { stenosis group } \\
(F F R \geq 0.80) \\
(n=96)\end{array}$ & p-value \\
\hline WBV at LSR & $43.90 \pm 22.30$ & $52.85 \pm 21.23$ & 0.003 \\
\hline WBV at HSR & $16.45 \pm 1.09$ & $16.89 \pm 1.03$ & 0.002 \\
\hline
\end{tabular}

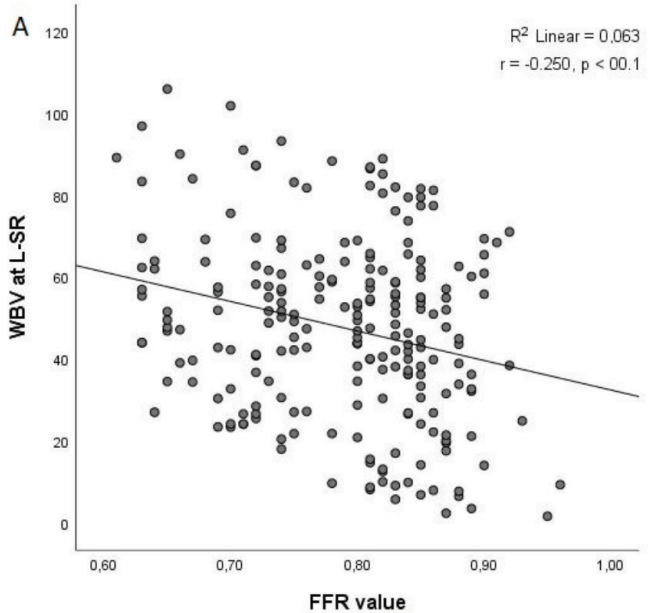

formulas have also been approved in large population studies $^{(4,7,8)}$. Many cardiovascular risk factors, including obesity, elderly, carotid intima-media thickness, and mitral annular calcification, are related to changes in rheological parameters ${ }^{(9,10)}$. It has also been shown that any change in hemorheological factors plays a crucial role in the atherosclerotic process ${ }^{(11-14)}$. The mechanisms underlying the increasing WBV in the critical stenosis (FFR <0.80) group can be explained by the plausible three causes

Table 3. Logistic regression analysis to determine the effects of variables on functionally critical coronary stenosis (FFR $<0.80$ )

\begin{tabular}{|l|l|l|l|}
\hline Variables & $\begin{array}{l}\text { Adjusted } \\
\text { OR }\end{array}$ & $\mathbf{9 5 \%} \mathbf{C l}$ & p-valu \\
\hline Model 1 & & & \\
\hline Hypertension & 1.359 & $0.778-2.375$ & 0.282 \\
\hline Diabetes mellitus & 0.629 & $0.350-1.131$ & 0.121 \\
\hline Smoking & 1.259 & $0.678-2.339$ & 0.465 \\
\hline WBV at LSR & 1.018 & $1.004-1.032$ & $\mathbf{0 . 0 1 0}$ \\
\hline Model 2 & & & \\
\hline Hypertension & 1.359 & $0.778-2.376$ & 0.281 \\
\hline Diabetes mellitus & 0.625 & $0.347-1.125$ & 0.117 \\
\hline Smoking & 1.221 & $0.652-2.287$ & 0.532 \\
\hline WBV at HSR & 1.446 & $1.094-1.912$ & $\mathbf{0 . 0 1 0}$ \\
\hline
\end{tabular}

FFR: Fractional flow reserve, HSR: High shear rate, LSR: Low shear rate, OR: Odds ratio, Cl: Confidence interval, WBC: White blood count, WBV Whole blood viscosity

Significant $p$-values are shown in bold.

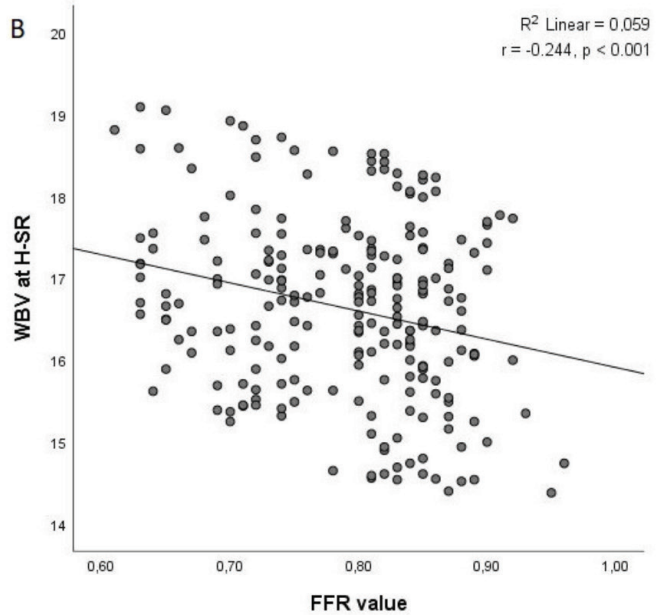

Figure 2. Correlation between FFR values with WBV at L-SR (A) and H-SR (B).

FFR: Fractional flow reserve, $H$-SR: High shear rate, L-SR: Low shear rate, WBV: Whole blood viscosity 
which are microvascular resistance, stenotic resistance, and endothelial dysfunction.

First, WBV is an intrinsic resistance of blood flow in the vascular system ${ }^{(11,15)}$. FFR is influenced by microcirculation because of being computed from the translesional pressure descent of epicardial coronary stenosis ${ }^{(16,17)}$. Changes in microvascular resistance in the existence of stenosis have an effect on hemodynamic factors used in the assessment of the stenosis in the examined blood vessels because FFR is affected by the combination of microvascular resistance and stenosis ${ }^{(18)}$. If the microvascular resistance during hyperemia increases, the FFR value decreases. Changes in microvascular resistance in the absence of stenosis during maximal hyperemia influence FFR. An important and independent relationship has been demonstrated between the coronary slow flow phenomenon and WBV in a previous study ${ }^{(19)}$.

Second, Dormandy et al. ${ }^{(20)}$ demonstrated whether the main source of circulatory failure in intermittent claudication was the peripheral artery stenosis or the increased blood viscosity. It was declared that in spite of serious symptoms of claudication, many patients with increased blood viscosity had normal arteriograms. In spite of an anatomically fixed stenosis, the growth in WBV resulting in augmented stenotic resistance may restrict the increase in blood flow after maximal vasodilatation and the corresponding increase in distal coronary pressure. It would be very useful for this likely mechanism to measure FFR at different viscosities from the same patient to exclude factors such as the absolute severity of coronary stenosis and distal coronary structure.

Third, blood viscosity is the crucial piece of endothelial shear stress, which is one of the main factors in endothelial function ${ }^{(21,22)}$. An increased WBV value has been represented to cause remodeling of the blood vessel and endothelial inflammation ${ }^{(23,24)}$. Besides the flow rate-related mechanical perspective, the high blood viscosity may have a further effect on FFR via leading to endothelial dysfunction which is another important put forward mechanism. Moreover, high blood viscosity is associated with hypertension, stroke, and metabolic syndrome, which are all related to chronic inflammation and endothelial dysfunction ${ }^{(25-28)}$.

\section{Study Limitations}

Our study should be appraised with some limitations. There was not directly a measured blood viscosity. Correspondence of WBV computed with a formula, with the direct measure of blood viscosity by a viscometer or the hemodynamic parameters related to endothelial shear stress, may raise the strength of the results. If measures of oxidative stress parameters and inflammatory agents have been obtained, they might have stronger results of the study because oxidative stress and inflammatory agents are accepted as the main contributors to blood viscosity and endothelial dysfunction ${ }^{(29)}$. Blood viscosity involves several ingredients crosslinked with each other, and these parameters maintain a physiologic visco-regulation. Compensatory alterations may mask changes in WBV. Appraisal of these parameters and of their relationship with WBV may present more comprehension of our outcomes.

\section{Conclusion}

This study demonstrated that high WBV levels have a relationship with the functional grade of angiographic intermediate coronary artery stenosis. WBV, which is a simple noninvasive test, should not be overlooked when evaluating FFR measurements. More investigations are required to explain the role of $\mathrm{WBV}$ in forecasting functional coronary artery stenosis.

\section{Ethics}

Ethics Committee Approval: Ethics committee approval was obtained from University of Health Sciences Turkey, Ankara City Hospital with the number of E1-202030 in 2021.

Informed Consent: Retrospective study.

Peer-review: Externally peer-reviewed.

\section{Authorship Contributions}

Surgical and Medical Practices: A.A., E.H.Ç., O.M., D.A., Concept: A.A., E.H.Ç., O.M., D.A., Design: A.A., 
E.H.Ç., O.M., D.A., Data Collection and/or Processing: A.A., Ö.Ç.K., M.A.E., M.O.Ö., Analysis and/or Interpretation: A.A., Ö.Ç.K., O.M., Literature Search: A.A., E.H.Ç., Ö.Ç.K., M.A.E., M.O.Ö., Writing: A.A., E.H.Ç.

Conflict of Interest: The authors report no financial relationships or conflicts of interest regarding the content herein.

Financial Disclosure: This research received no specific grant from any funding agency.

\section{References}

1. Pijls NH, Sels JW. Functional measurement of coronary stenosis. J Am Coll Cardiol 2012;59:1045-57.

2. de Simone G, Devereux RB, Chinali M, et al. Association of blood pressure with blood viscosity in american indians: the Strong Heart Study. Hypertension 2005;45:625-30.

3. Lee SR, Jung JM, Jung LY, et al. Elevated coronary whole blood viscosity in acute coronary syndrome patients. Clin Hemorheol Microcirc 2013;55:85-94.

4. de Simone G, Devereux RB, Chien S, Alderman MH, Atlas SA, Laragh $\mathrm{JH}$. Relation of blood viscosity to demographic and physiologic variables and to cardiovascular risk factors in apparently normal adults. Circulation 1990;81:107-17.

5. Xaplanteris P, Fournier S, Pijls NHJ, et al. Five-Year Outcomes with PCI Guided by Fractional Flow Reserve. N Engl J Med 2018;379:250-9.

6. Nwose EU, Richards RS. Whole blood viscosity extrapolation formula: Note on appropriateness of units. N Am J Med Sci 2011;3:384-6.

7. Høieggen A, Fossum E, Moan A, Enger E, Kjeldsen SE. Whole-blood viscosity and the insulin-resistance syndrome. J Hypertens 1998;16:203-10.

8. Tamariz LJ, Young JH, Pankow JS, et al. Blood viscosity and hematocrit as risk factors for type 2 diabetes mellitus: the atherosclerosis risk in communities (ARIC) study. Am J Epidemiol 2008;168:1153-60.

9. Velcheva I, Antonova N, Titianova E, Damianov P, Dimitrov N, Ivanov I. Hemorheological parameters in correlation with the risk factors for carotid atherosclerosis. Clin Hemorheol Microcirc 2006;35:195-8

10. Ozcan Cetin EH, Cetin MS, Canpolat U, et al. The Forgotten Variable of Shear Stress in Mitral Annular Calcification: Whole Blood Viscosity. Med Princ Pract 2015;24:444-50.

11. Lowe GD, Lee AJ, Rumley A, Price JF, Fowkes FG. Blood viscosity and risk of cardiovascular events: the Edinburgh Artery Study. Br J Haematol 1997;96:168-73.

12. Kensey KR, Cho YI, Chang M. Effects of Whole Blood Viscosity on Atherogenesis. J Invasive Cardiol 1997;9:17-24.

13. Koenig W, Sund M, Filipiak B, Döring A, Löwel H, Ernst E. Plasma viscosity and the risk of coronary heart disease: results from the MONICAAugsburg Cohort Study, 1984 to 1992. Arterioscler Thromb Vasc Biol 1998;18:768-72.
14. Sloop G, Holsworth RE Jr, Weidman JJ, St Cyr JA. The role of chronic hyperviscosity in vascular disease. Ther Adv Cardiovasc Dis 2015;9:19-25.

15. Rosenson RS, McCormick A, Uretz EF. Distribution of blood viscosity values and biochemical correlates in healthy adults. Clin Chem 1996;42:1189-95.

16. Verhoeff BJ, van de Hoef TP, Spaan JA, Piek JJ, Siebes M. Minimal effect of collateral flow on coronary microvascular resistance in the presence of intermediate and noncritical coronary stenoses. Am J Physiol Heart Circ Physiol 2012;303:H422-8

17. Layland J, Burns AT, Somaratne J, Whitbourn RJ. Looks can be deceiving: dissociation between angiographic severity and hemodynamic significance of a lesion. The importance of microvascular resistance. Cardiovasc Revasc Med 2011;12:258-61.

18. Meuwissen M, Chamuleau SA, Siebes M, et al. Role of variability in microvascular resistance on fractional flow reserve and coronary blood flow velocity reserve in intermediate coronary lesions. Circulation $2001 ; 103: 184-7$

19. Cetin MS, Ozcan Cetin EH, Canpolat U, et al. An overlooked parameter in coronary slow flow phenomenon: whole blood viscosity. Biomark Med 2015;9:1311-21.

20. Dormandy JA, Hoare E, Postelthwaite J. Importance of blood viscosity in rheological claudication. Plast Reconstr Surg 1975;55:720.

21. Yaylali YT, Susam I, Demir E, et al. Increased red blood cell deformability and decreased aggregation as potential adaptive mechanisms in the slow coronary flow phenomenon. Coron Artery Dis 2013;24:11-5.

22. Cutri N, Zeitz C, Kucia AM, Beltrame JF. ST/T wave changes during acute coronary syndrome presentation in patients with the coronary slow flow phenomenon. Int J Cardiol 2011;146:457-8.

23. Silber HA, Bluemke DA, Ouyang P, Du YP, Post WS, Lima JA. The relationship between vascular wall shear stress and flow-mediated dilation: endothelial function assessed by phase-contrast magnetic resonance angiography. J Am Coll Cardiol 2001;38:1859-65.

24. Sercelik A, Besnili AF. The Contribution of Whole Blood Viscosity to the Process of Aortic Valve Sclerosis. Med Princ Pract 2018;27:173-8.

25. Damaske A, Muxel S, Fasola F, et al. Peripheral hemorheological and vascular correlates of coronary blood flow. Clin Hemorheol Microcirc 2011;49:261-9.

26. Vayá A, Hernández-Mijares A, Bonet E, et al. Association between hemorheological alterations and metabolic syndrome. Clin Hemorheol Microcirc 2011;49:493-503.

27. Olausson EA, Kilander A. Glycaemic index of modified cornstarch in solutions with different viscosity. A study in subjects with diabetes mellitus type 2. Clin Nutr 2008;27:254-7.

28. Tikhomirova IA, Oslyakova AO, Mikhailova SG. Microcirculation and blood rheology in patients with cerebrovascular disorders. Clin Hemorheol Microcirc 2011;49:295-305

29. Smart SC, Bhatia A, Hellman R, et al. Dobutamine-atropine stress echocardiography and dipyridamole sestamibi scintigraphy for the detection of coronary artery disease: limitations and concordance. J Am Coll Cardiol 2000;36:1265-73. 